\title{
SUJEITO IMORTAL, SUJEITO INTERPASSIVO: A AMBIGUIDADE DA PERSONAGEM ÉPICA
}

\author{
Míriam Zafalon* \\ Marisa Corrêa Silva** \\ Universidade Estadual de Maringá
}

Resumo: Transcendendo as potencialidades humanas, o animal humano atinge o status de imortal quando resiste e supera a si mesmo. Assim ocorreu com os mártires cristãos e também com os arquétipos da épica universal. Para Badiou (2002), a imortalidade, em síntese, consiste na atitude do homem que se torna sujeito diante de um evento, ou seja, que, a partir de um momento de epifania, entrega-se à verdade do acontecimento ímpar, sendo convocado a uma fidelidade. Por outro lado, para além do processo de imortalidade, o conceito de interpassividade, exposto a partir dos estudos de Slavoj Žižek (2006) e da sua leitura da obra lacaniana, desvenda outra face para as personagens épicas, uma vez que os heróis das epopeias agem por obra dos deuses olímpicos; mesmo aparentando uma personalidade ativa, as personagens não agem por livre e espontânea vontade, mas para cumprir os planos préestabelecidos pelas divindades. Pretende-se, neste artigo, refletir sobre a dialogia sujeito imortal X sujeito interpassivo, apontando marcas de ambos os domínios no mundo épico.

Palavras-chave: Imortalidade. Interpassividade. Personagem Épico.

\section{Introdução}

Slavoj Žižek (2006) apresenta a interpassividade como a estranha relação que construímos com objetos que ocupam o nosso lugar na situação de passividade. Alguns dos exemplos que ele cita são: o indivíduo que estoca centenas de filmes para assistir "um dia" (ele menciona o VCR, mas pode-se pensar hoje em quem os baixa da internet), enquanto usa seu tempo em outras coisas; o comercial de refrigerante que diz "Oh, que sabor!", antecipando a reação do consumidor ideal; a obsessão do acadêmico liberal ocidental com o sofrimento em países periféricos, que permitem que ele sofra lendo as reportagens, enquanto
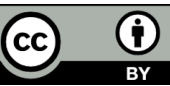

Esta obra está licenciada sob uma Creative Commons - Atribuição 4.0

\footnotetext{
* Doutora em Letras - Estudos Literários - pela Universidade Estadual de Maringá e mestre em Letras pela mesma instituição. Professora QPM do Colégio de Aplicação Pedagógica da Universidade Estadual de Maringá. E-mail: mzafalon@bol.com.br.

** Doutora em Letras pela Universidade Estadual Paulista Júlio de Mesquita Filho e mestre em Comunicação pela mesma instituição.Tem pós-doutorado na Rutgers - the State University of New Jersey. Atualmente é professor associado no Departamento de Letras da Universidade Estadual de Maringá. Pioneira no Brasil na aplicação sistemática do materialismo lacaniano de Slavoj Zizek e de Alain Badiou na análise literária. E-mail: mcsilva5@uem.br.
} 
continua calmamente a perseguir a carreira; e Cristo, que salva a humanidade ao assumir passivamente o fardo dos pecados. Ele nota que frequentemente atividade e passividade podem se misturar, como no choro de luto, que é passivo (reação ao sofrimento) e ativo (prática simbólica ritualizada e ativa).

A interpassividade seria, portanto, um movimento da subjetividade que consiste em exteriorizar a passividade mais profunda do indivíduo, por intermédio de sua interação com o computador e com outros elementos midiáticos, ou ainda por ação de indivíduos que cumprem a função passiva (como as carpideiras numa cerimônia fúnebre). Tal conceito é bastante utilizado em psicanálise em conjunto com a estrutura da crença, mas em Žižek ele também funciona para análise dos mecanismos através dos quais as sociedades ocidentais contemporâneas manipulam a ilusão de autonomia dos sujeitos. Em consonância com essa visão contemporânea do papel passivo do homem frente à realidade, é possível encontrar na épica um formato parecido, também alienante, de personagens que se sentem donos de suas atitudes, embora estejam somente cumprindo destinos que escapam ao seu arbítrio.

Embora Lukács tenha sido bastante criticado por idealizar a sociedade grega, omitindo suas contradições internas, o conceito de totalidade ainda faz sentido para caracterizar aspectos da representação de mundo na epopeia. Na épica, a ligação entre o que se faz e o que se é está muito próxima. Isso se justifica porque na narrativa épica almeja-se a glória, a solução e não os enigmas. O herói épico segue a homogeneidade da cultura fechada, vivendo num mundo palpável, cuja consciência consegue abarcar em sua plenitude. Sobre a totalidade da epopeia, explica Lukács (2000, p. 31):

Pois totalidade, como prius formador de todo fenômeno individual, significa que
algo fechado pode ser perfeito; perfeito porque nele tudo ocorre, nada é excluído e
nada remete a algo exterior mais elevado; perfeito porque nele tudo amadurece até a
própria perfeição e, alcançando-se, submete-se ao vínculo. Totalidade do ser só é
possível quando tudo já é homogêneo, antes de ser envolvido pelas formas; quando
as formas não são uma coerção, mas somente a conscientização, a vinda à tona de
tudo quanto dormitava como vaga aspiração no interior daquilo a que se devia dar
forma; quando o saber é virtude e a virtude, felicidade; quando a beleza põe em
evidência o sentido do mundo.

A ideia de totalidade traz certa legitimidade à ação das personagens e acaba por camuflar a real situação do sujeito épico: a partir da sistematização de ideias de Lukács, tratase de um ser totalmente dominado pelos desígnios divinos. Compõem-se, dessa maneira, um sujeito empírico em sua vivência, ou seja, seu conhecimento pauta-se em sua experiência de vida. Esse esquema tão equilibrado, segundo Lukács (2000, p. 29), é possível porque “O mundo do sentido é palpável e abarcável com a vista, basta encontrar nele o locus destinado 
ao individual".

Ainda para Lukács, o homem épico grego é o símbolo do coletivo; ele é, enfim, a essência, livre de abismos, repleta de totalidade. Por isso mesmo, podemos entender que esse homem é fundamentalmente interpassivo, por sua total impotência em decidir seu próprio destino.

Quanto ao conceito de "imortalidade", por meio do estudo da teoria de Alain Badiou em sua obra Ethics: An Essay on the Understanding of Evil (2002), é possível depreender que o filósofo está vinculado à "ética da verdade", uma ética específica que atenta para a seguinte reflexão: o Mal só pode existir a partir do Bem e da Verdade. Badiou formula três teses que norteiam o seu pensamento. Na tese um, afirma que o homem é identificado pelo pensamento afirmativo, por suas verdades individuais e pelo sentimento de Imortalidade ${ }^{1}$ que o faz o mais contraditório dos animais. Na tese dois, explica que o Mal é determinado pelo Bem, ou seja, só se pode conceituar e compreender o sentido do Mal quando se estabelece o que é o Bem. Finalmente, na tese três, afirma que uma ética geral, enquanto absoluta e desvinculada de contingências, não existe; há sim, situações em que se aplicam processos éticos.

Tais teses fazem parte da formulação do pensamento-chave da filosofia de Badiou: o que realmente importa em meio às verdades de nosso tempo, para formular um conceito possível de ética, é o reconhecimento do mesmo e não do outro. No dizer do filósofo, a verdade é igual para todos, fato que colabora para que não se vinculem as questões éticas apenas ao suposto respeito pelas diferenças culturais.

Desta forma, Badiou (1994) analisa o sujeito contemporâneo e entende que a capacidade deste indivíduo para ser "verdadeiro" é o que pode fazer dele um "imortal", resistente à passividade. Segundo o autor, o homem passa a ser sujeito quando recebe um chamado para ser imortal:

O direito do Homem é primeiramente o direito à resistência humana. Ao fím, morremos todos nós e só resta o pó. Há, entretanto, uma identidade de Homem como imortal, no instante em que ele afirma o que é, contra o querer-ser-um-animal ao qual a circunstância o expõe. Cada homem, isto é por demais sabido, é capaz de ser imortal; em grandes ou pequenas circunstâncias, por uma verdade importante ou secundária, isto pouco importa (BADIOU, 1994, p. 108).

O pensamento de Badiou faz refletir sobre um sujeito contemporâneo cuja identidade é líquida (BAUMAN, 2005), ou seja, mutável e adaptável às situações cotidianas. Se por um lado somos meros mortais, repletos de todas as fraquezas humanas, por outro, podemos nos

\footnotetext{
1 "Imortalidade" significa, para Badiou, a capacidade humana de resistir aos conceitos pré-determinados, a evasão dos interesses que regulam o pensar e o agir individualistas, fazendo o homem superar-se a si mesmo.
} 
tornar imortais quando ultrapassamos as ideias pré-determinadas de sujeito e alcançamos um sentido humano que perdurará mesmo após nossa passagem. O homem busca, durante toda a sua existência, fatos que possam imortalizá-lo, potencializando sua natureza em relação às vicissitudes do mundo.

A discussão delineada nestas linhas diz respeito a polos, aparentemente, opostos, a saber, interpassividade $\mathrm{X}$ imortalidade, teorias contemporâneas que podem ser inferidas por intermédio do comportamento do homem de nosso tempo. É arriscado, portanto, postular as seguintes questões: o herói épico pode comportar as especificidades da interpassividade? É possível compreender a personagem épica como um ser imortal? A partir destes questionamentos, porém, podem ser lançadas luzes no estudo da épica. Tal possibilidade levanos a empreender o presente estudo.

\section{Sobre a interpassividade}

A interpassividade pode resultar ou ser parte de um tipo de alienação do indivíduo em favor de uma falsa ideia de autenticidade dentro da sociedade. A atividade humana influenciada pela tecnologia adquire um certo ar de "naturalidade" da qual o homem contemporâneo não consegue fugir, ou, sequer, perceber. Eis que surge, então, a noção do homem-objeto, passivo em relação ao seu próprio destino, embora, diferentemente do herói das epopeias homéricas, o indivíduo do nosso tempo seja objeto das máquinas e não dos deuses.

A onipresença da informação e do factoide na contemporaneidade é objeto de um sem-número de reflexões; ainda nos primórdios desse processo, Benjamin (1994, p. 203) já afirmava que vivemos na sociedade do imediatismo:

\footnotetext{
Cada manhã recebemos notícias de todo o mundo. E, no entanto, somos pobres em histórias surpreendentes. A razão é que os fatos já nos chegam acompanhados de explicações. Em outras palavras: quase nada do que acontece está a serviço da narrativa, e quase tudo está a serviço da informação.
}

A libertação ou emancipação do homem de hoje, portanto, se concretizaria em relação à tecnologia e à mídia. Em seus estudos, o esloveno Slavoj Žižek aponta para a categoria interpassiva de sujeito, contradizendo a dominante condição de interatividade. $\mathrm{O}$ sujeito interpassivo é, nesse sentido, completamente hodierno e insere-se na discussão sobre a interação com as máquinas e sobre os nossos conceitos.

Segundo Moura (2004), nossa sociedade vem sendo construída sob o signo do discurso hegemônico, massificado pela compulsão ao consumo. Sob a capa da democracia e 
da livre expressão, vive-se num mundo cujo sistema é totalitário. A imagem do Outro é uma forma de policiamento às nossas consciências, fazendo-nos agir de acordo com as previsões que já foram determinadas, de forma a tornar o ser humano um prisioneiro desse poder central, que manipula as situações e elabora o pensamento das pessoas

Para Žižek (2006), a interpassividade consiste em fingir que o que está posto funciona. Segundo o autor, vivemos numa sociedade em que os princípios básicos para estar bem são: consumir, acreditar e obedecer. A ideologia reinante, reforçada pelos meios de comunicação e publicidade, doutrina para essa vida subjetivamente passiva, muitas vezes imperceptível para as pessoas. E o capitalismo, que empurra para o consumo, procura dar um significado à vida das pessoas, incutindo nelas a vontade de aproveitar o melhor possível seu dia, mascarando os reais problemas existentes.

Žižek destaca a figura do Outro (o Autre lacaniano, referido em inglês como Big Other) como a grande voz que tem o potencial de experienciar por nós os sentimentos e atitudes do cotidiano. O teórico mostra, em How to read Lacan (2006), que o Outro se apresenta em diversas formas e situações: pode ser o coro num espetáculo teatral, as "carpideiras" que são contratadas para chorar pelos mortos, as risadas gravadas ao fundo das cenas de programas de humor. Nessas e em muitas outras situações, o Outro executa a nossa ação por nós e ficamos passivos ante essa ocupação do nosso espaço individual.

A interpassividade atua para que as coisas continuem exatamente como estão e não para que haja mudanças, permitindo uma ilusória sensação de "normalidade", de que tudo está no seu devido lugar. Segundo Žižek (2006, p. 26), a "pseudoatividade", ou seja, a tentativa de participar e ser ativo envolve os indivíduos, muitas vezes, em atividades e debates sem sentido, em favor de uma aparente liberdade de expressão crítica, que, sabe-se, os manterá longe da real situação a qual deveriam compreender e mudar. A proposta radical de Žižek (2006) é a recusa pela participação, é dizer não à interação, para assim, tentar reverter o quadro de interpassividade que se apresenta.

Para Lacan, o sujeito não possui integralidade: ele é "fraturado", falta-lhe uma parte essencial. Trata-se de um sujeito dividido, cuja lacuna é constitutiva (ou seja, não existe sujeito antes do corte primordial) e o seu desejo é o resultado do "desejo do Outro". Percorrendo o caminho do sujeito lacaniano, percebe-se que, para Žižek, o sujeito interpassivo não faz escolhas; apenas endossa opções que o grande Outro lhe impõe como verdades, é o sujeito passivo através do Outro.

Diferentemente do sujeito interpassivo ou do sujeito "barrado" (nome lacaniano para 
o ser humano que passou pelo corte primordial), o sujeito imortal, para Badiou, encarna em potência máxima a subjetividade, revelando a natureza humana através de um legado singular. Passemos a algumas ideias sobre o conceito de imortalidade, observando as especificidades desta linha de pensamento.

\section{Sobre a imortalidade}

Quando se pensa no tema imortalidade, uma das primeiras ideias que vêm à mente é a constituição de seres (deuses) que não morrem, tendo uma existência eterna. Arendt (1987) postula que, vista desta forma, a imortalidade representa o tempo contínuo, cuja vida a autora denomina como "contemplativa", diferenciando o ser humano do animal irracional. Para a filósofa, a imortalidade é conquistada apenas pelos melhores entre os seres humanos, aqueles que não se satisfazem com a vida oferecida, buscando na autêntica existência, o caminho para ser imortal.

Pode-se ainda intuir a respeito do tema da imortalidade da alma, cuja preocupação do ser humano remonta há centenas de séculos e está diretamente ligada ao campo da religião. Indubitavelmente, a tese de que a alma sobrevive após a morte terrena do ser humano é amplamente propagada pelas doutrinas religiosas e pela filosofia. Os órficos já debatiam a tese filosófico-cultural de que "[...] a alma humana é imortal porque divina" (ZILLES, 2003, p.606). Zilles explicita o pensamento de Platão, que acreditava que a alma é imortal por pertencer ao mundo invisível e não ao mundo sensível ao qual pertence o corpo. Portanto, não se corrompe pela morte, é imutável e indissolúvel. Seguindo o raciocínio platônico, discutir o tema da imortalidade da alma é refletir sobre a luta travada pelo homem contra a morte e seus efeitos.

Já a ideia de imortal, postulada por Badiou, é o resultado de um processo de autoafirmação humana, que consiste em o homem deixar de ser a vítima, o "animal-para-amorte", tornando-se potente, singularizado, em contato íntimo com acontecimentos que levam à "verdade". Trata-se de um conceito diferente do que o senso comum e as teorias filosóficas em geral estabelecem como imortal.

A compreensão sobre o conceito de imortal, em Badiou, prescinde de esclarecimentos a respeito da ética vigente no mundo contemporâneo e da "ética das verdades", ilustrada pelo autor. O homem hodierno entende ética como um "princípio de julgamento das práticas de um Sujeito, seja ele individual ou coletivo" (BADIOU, 1995, p. 16). Eis aí o ponto chave que determina o extermínio da singularidade dos sujeitos, segundo o autor: a universalização dos direitos do homem torna-o massificado. A imposição do 
tratamento igualitário, baseado numa ética construída sobre conceitos abstratos, gera um simulacro de igualdade e similitude, criando a falsa noção de um sujeito universal, cujos direitos são e devem ser iguais para qualquer cultura.

O multiculturalismo, a tolerância, o reconhecimento do outro são algumas das ideias constantes na ética universalizante. Badiou alerta que todos estes conceitos estão distantes da ética verdadeira, tratando-se de um "manual" contemporâneo, que não condiz com o real sentido ético que deve ser assimilado pelos sujeitos, portanto, não podem ser sustentados. $\mathrm{Na}$ verdade, o respeito às diferenças só existe até certo ponto, há sempre desconfiança e até mesmo inaceitabilidade por hábitos de outros povos que sejam considerados bárbaros. Não se enxerga o outro como superior; o outro só é aceito quando se assemelha a nós, portanto, quando ele não está distante de nossas concepções de ser humano. Além disso, só se respeitam as diferenças daqueles que também conseguem respeitar as dos outros indivíduos. Nisso não há mérito algum, pois aquele que não age segundo a ética dominante torna-se excluído do convívio social, pelo menos até que se adapte às regras impostas pela ética universal.

Em termos lacanianos, o começo do processo de subjetivação se dá quando o indivíduo rompe com a comunhão materna, o corte traumático que o encaminha ao campo simbólico. Após esse corte, que ocorre do Nome do Pai à relação edipiana, o rompimento faz com que o homem se constitua sujeito, busque preencher seus vazios e, possa, eventualmente, ser colocado frente a frente com o âmbito do Real, às vezes por um acontecimento trágico ou traumático, que poderá fazê-lo tomar posições e executar posturas que o elevem à condição de imortal.

Recusando o sujeito universal vitimizado, Badiou problematiza o papel do homem que busca reconhecer o Mesmo, em detrimento da alteridade que realiza no Outro lacaniano, na instância sem nome e onipresente que o cerca e observa, dando forma a seus desejos e tendo de ser poupado de conhecer seus segredos "obscenos". O autor afirma que o Bem passa pela vida e o homem precisa estar atento a esse movimento, para deixar de ser "besta sofredora", cuja identidade de ser vivo condena-o à posição de "ser-para-morte", e apenas isso. Para mudar de perspectiva, o ser humano se compõe como sujeito, singulariza-se em relação à existência mesquinha, alcança a condição de "imortal". Conhecer a verdade torna possível o aparecimento do sujeito, aparição rara, que passa a ligar-se ou a promover um evento. Tal sujeito é capaz de produzir uma ética que ultrapassa os limites do "dever-ser", indo além da conceituação de ética das diferenças. Trata-se do surgimento do sujeito imortal. 
Quanto às personagens épicas, é possível vislumbrar em sua composição traços da imortalidade explicitada por Badiou, visto tratarem-se de seres que são fiéis a um evento de grande importância. Por outro lado, pode-se inferir que as personagens do mundo épico, pelo viés de Lukács (2000), são conduzidas pelas mãos dos deuses do Olimpo, fato que confere a elas uma situação passiva. Para suscitar tal contradição, a trajetória do herói Aquiles serve-nos como modelo.

\section{Aquiles: herói interpassivo ou imortal?}

Para Lukács (2000), o herói épico representa um mundo que evolui homogeneamente, coloca-se à disposição da coletividade, extirpando quaisquer sentimentos ou aspirações pessoais, desenvolve seu papel de acordo com uma previsão imposta pelos deuses que também intervêm quanto aos procedimentos que os sujeitos devem executar, às batalhas que devem lutar, às vitórias ou derrotas que devem obter. Lukács (2000, p. 87) afirma: "O herói da epopeia nunca é, a rigor, um indivíduo. Desde sempre se considerou traço essencial da epopeia que seu objeto não é um destino pessoal, mas o de uma comunidade". Trata-se de um herói que não se apresenta dividido, ele apenas cumpre os planos que lhe cabem. Lukács (2000, p. 26) expõe o herói épico como um ser grandioso nas ações exigidas por aquele modo de pensar e viver:

\footnotetext{
Não é a falta de sofrimento ou a segurança do ser que revestem aqui homens e ações em contornos jovialmente rígidos (o absurdo e a desolação das vicissitudes do mundo não aumentaram desde o início dos tempos, apenas os cantos de consolação ressoam mais claros ou mais abafados), mas sim a adequação das ações às exigências da alma: à grandeza, ao desdobramento, à plenitude.
}

Para Fehér (1972) a epopeia representa sociedades nas quais os indivíduos estavam plenamente inseridos. É um gênero que se difere do romance e das formas narrativas modernas, nas quais a totalidade espontânea do ser já não é mais possível. O Destino, divindade cega e inexorável, submete os heróis épicos e a regulamentação das instituições épicas através da imposição dos deuses do Olimpo, que determinam atitudes e consequências das personagens. Em contraponto, observa-se no modelo épico um mundo no qual os seres fantásticos tornam-se singulares em suas ações; uma vez que sejam colocados em contato com uma verdade, cumprem fidelidade em relação a ela, sendo capazes de assumir um movimento de ruptura com a realidade vigente e de atitudes extremas de coragem e despreendimento material e vital. São sujeitos imortais na medida em que se subjetivam por uma causa pública, tornando-se universais uma vez que se mantêm fiéis à verdade resgatada pelo evento. $\mathrm{Na}$ épica, assim como na vida cotidiana, um evento é um momento, uma situação que se difere 
sobremaneira dos planos diários e comuns de vida, instigando o homem a tornar-se sujeito, a decidir-se por uma maneira nova de ser e agir.

O processo de singularização do sujeito não pode ser entendido como individualização ou egocentrismo; ao contrário, o ser da épica grega caracteriza-se por um sentido de coletividade, por pensar no bem comum e por ser dotado de uma subjetividade emancipatória. E essa é a questão-chave para diferenciar o Evento do falso Evento: o falso Evento pode provocar fidelidade (e Badiou não foge do exemplo clássico do nazismo), mas nunca possui uma feição verdadeiramente emancipatória: antes, é de feição conservadora, lutando para manter ou restabelecer privilégios. Assim, na internalidade da cultura épica, a emancipação possível é limitada, como Féher (1972) reconheceu. Dentro das coordenadas dessa cultura, o único Evento-verdade possível é manter-se fiel à própria natureza e destino, buscando a existência autêntica - que é menos problemática do que para o sujeito contemporâneo.

Aquiles é um dos heróis mais conhecidos e mais poderosos do mundo épico. É o protótipo do homem forte, com características sobre-humanas que o destacam diante dos outros homens. Teve o poder de escolha sobre o rumo de seu destino e preferiu uma vida gloriosa e breve a uma existência longa, mas rotineira e apagada. Aquiles pode ser compreendido como um sujeito imortal, uma vez que perseverou no processo de verdade, alguém que deixou o conforto de uma vida calma e comum, declarando sua subjetividade, sem receio das consequências. Portanto, o herói tornou-se "o suporte de uma fidelidade. Logo, o suporte de um processo de verdade" (BADIOU, 1994, p. 110).

Todavia, ainda que represente o heroísmo exaltado, alerta-se para o fato de que tanto Aquiles quanto outros heróis épicos não escolhem suas ações por intermédio de sua própria vontade, mas, sim, são instrumentos de um plano orquestrado pelos deuses do Olimpo, ou seja, dizer que Aquiles escolheu seu destino significa que ele cumpriu os planos determinados pelas divindades, a quem todos os destinos são conferidos. Aquiles era filho de Tétis e de Peleu. Ao nascer, a mãe o mergulhou no Estige para torná-lo invulnerável. Mas a água não lhe chegou ao calcanhar, pelo qual ela o segurava, e que assim se tornou seu ponto fraco - o proverbial "calcanhar de Aquiles" (COMELLIN, s/d). Quando Tétis, mãe de Aquiles, o consola por ter sido ultrajado por Agamenon, observa-se em sua fala a predestinação de seu filho:

Oh, meu filho! Por que te concebi para um tão desgraçado destino? Por que não podes ficar, sem lágrimas e livre de pesares, junto aos navios, já que teu destino é curto e não durarás muito tempo? Bem cedo te pesou a condenação e o infortúnio. 
Nessa perspectiva, a figura de Aquiles reforça a ideia de que, na epopeia, "Ser e destino, aventura e perfeição, vida e essência são então conceitos idênticos” (LUKÁCS, 2000, p. 26-27).

Ainda que o herói Aquiles viva num círculo fechado e completo, assemelhando-se ao indivíduo interpassivo que sobrevive preso à sua noção errônea de interatividade, é possível analisá-lo como um sujeito pensante, capacitado para uma linguagem que evoca sua cultura e tradições, movido pelo desejo de agir e de ser, de possuir uma ética e uma identidade. Para atingir a imortalidade, Aquiles foi capaz de "aceitar" um destino que lhe oferecia glórias e uma breve existência, mantendo-se de olhos abertos e atentos à verdade que se lhe apresentava: a iminência de uma guerra. Sendo fiel a este evento, Aquiles suplanta, de certa forma, a predisposição delineada pelos deuses, tendo a coragem de agir por sua conta e risco, abandonando a certeza de uma vida comum, sem arroubos de heroísmo e bravura.

Contrapondo as noções teóricas, mais uma vez, é preciso ressaltar que o mundo da totalidade em que Aquiles foi feito herói é muito diferente da fragmentariedade da época atual. Não obstante essa dialogia, percebe-se que na constituição da sociedade contemporânea há tentativas tortas de manter uma certa homogeneidade, com vistas a adaptar as pessoas às situações postas. O sujeito interpassivo é o modelo do ser participativo, mas que não faz diferença alguma, ele é encaminhado a possíveis decisões que são propostas pela ideologia dominante.

Numa perspectiva lacaniana, o inconsciente se materializa no desejo do Outro e, para que o Outro deixe de exercer poder sobre as ações do sujeito, deve haver uma destituição subjetiva, ou seja, há uma desresponsabilização do Outro em relação ao indivíduo, tornando o sujeito o único detentor de sua vitória ou seu sofrimento. A figurativização do Outro na trajetória de Aquiles consiste na sua própria ação que o torna objeto de si mesmo, ele é um sujeito que age pela coletividade, que espera dele atitudes heroicas de um semideus, e, nas palavras de Lukács (2000), pelo "dever-ser", ou seja, a morte de sua espontaneidade que obriga o herói épico a ser exatamente o que aparenta, pois essência e aparência devem seguir lado a lado na epopeia grega. O Outro representa o significante, aquela entidade que vivencia, que absorve, que propriamente materializa cada um dos comportamentos do sujeito interpassivo.

Apesar da aparente evidência da presença do Outro na ação do herói épico Aquiles, é necessário voltar a Badiou (1994, p. 45) quando afirma "Um sujeito é primeiramente aquilo 
que fixa um evento indecidível, porque assume o risco de decidi-lo". O herói da guerra de Troia arriscou-se quando preferiu a fama ao obscurantismo, a morte à vida; combateu, assim, as formas de dominação, a submissão e a passividade, fazendo de seu destino um modo de vida. Para Badiou, esse sujeito singular é construído pela ética da verdade, surgindo no interior de um dado evento, que vem para afirmar-se como novidade, ultrapassando a realidade cristalizada.

O evento (acontecimento), que faz surgir o sujeito, é o que Lacan denomina como “impensável”. Trata-se do momento em que o Real é tocado, em detrimento do campo Simbólico que se faz necessário para sobrevivência cotidiana. Quando Aquiles excede o mundo Simbólico, passando ao domínio do Real em favor de seu chamado pessoal às armas, protagoniza uma ruptura, tornando-se apto para sustentar sua imortalidade, abandonando as identificações imaginárias e a posição de vítima, para assumir a possibilidade de "ser".

Entretanto, preconizando a teoria da interpassividade, pode-se entrever que o mesmo acontecimento faz de Aquiles um herói imortal e um sujeito interpassivo. Apesar de o sujeito interpassivo viver num contexto infinitamente maior que o do mundo grego, ele traz em si a ideologia da "perfeição", que o aproxima cada vez mais dos heróis épicos: o mundo épico é perfeito, segundo Lukács (2000, p. 31):

[...] porque nele tudo ocorre, nada é excluído e nada remete a algo exterior mais elevado; perfeito porque nele tudo ocorre, nada é excluído e nada remete a algo exterior mais elevado; perfeito porque nele tudo amadurece até a própria perfeição e, alcançando-se, submete-se ao vínculo.

A concepção lacaniana explica que o homem identifica-se com a imagem do Outro, isto é, o indivíduo quer chegar o mais perto possível de sua completude, demonstrando que a condição humana persegue um sentido que não se encontra em lugar algum. O Outro é a constituição da imagem do eu em busca da ilusão de completude do ser. Aquiles projeta no Outro o seu destino de heroísmo, a questão de sua existência, acomodando-se, inconscientemente, à sua interpassividade, e, até mesmo, responsabilizando o Outro pelo cumprimento de seu dever.

Entretanto, Aquiles é um sujeito raro que recebeu uma convocação para estar em contato com uma eventual verdade - que não é simplesmente a Guerra de Troia, nem seu destino prefigurado, mas a crença no significado da sua escolha: atender ao chamado eterniza um ato concreto e deixa de submetê-lo à sociedade desigual, custando-lhe a vida. Nesse contexto, o herói grego deixa a unidade da épica, e não pode ser igualado a todos os seres humanos, como se fizesse parte de uma ética universal. Pelo contrário, mostra-se um sujeito 
similar ao sujeito da contemporaneidade, que não aceita uma realidade confortável e aspira a algo que exige seu sacrifício. De alguma forma, mesmo que por influência dos deuses, ele se potencializa na afirmação da ocorrência que o torna imortal.

\section{Conclusão}

Mantendo o distanciamento de comprovações levianas, tentamos demonstrar nestas páginas a heterogeneidade da personagem épica, por meio da reflexão sobre dois conceitos concebidos no interior do materialismo lacaniano: imortalidade e interpassividade.

Segundo Berman (1998), o espírito de modernidade é caracterizado pelo desejo de desenvolvimento e de revolução da sociedade; na busca desse novo, a sociedade se torna cada vez mais fragmentada, sem consistência, fato que pode ser compreendido por meio dos excessos da era virtual. O discurso capitalista, que aprisiona os indivíduos no consumismo como forma de lidarem com seus problemas internos, que os faz sentir interativos dando-lhes a falsa ilusão de participação, segundo Žižek, representa uma forma de escravidão. Para o teórico esloveno, o sujeito precisa se posicionar politicamente para fugir dessa prisão, e não deixar que a interpassividade transmita uma ideia de ordem, de que tudo está absolutamente "normal".

Em Aquiles, encontramos esse movimento de alienação passiva, que, muito distante do processo tecnológico, é também uma limitação para a emancipação do sujeito. O herói mais conhecido de A Ilíada anula-se enquanto sujeito, e sua identidade passa a ser a identidade coletiva, sua consciência do mundo, seu senso crítico, não passam de uma imagem formatada que o faz agir e pensar como se comandasse a si próprio.

O mesmo movimento que pode ser interpretado como anulação do ser diante dos desígnios divinos é marca premente da mudança de comportamento do indivíduo em relação ao Simbólico: a posição de vítima deixa de ser ocupada, o evento convoca o sujeito que acaba de nascer a uma fidelidade que o perpetuará, passando a ser a nova maneira de regular o estarno-mundo. A passagem ao mundo da imortalidade (vale dizer à posição de sujeito) estabelece um novo parâmetro para a existência, apresenta uma resposta à crise do Simbólico que está instaurada desde tempos imemoriais. Badiou, retomando a filosofia lacaniana, expõe a necessidade da revolução subjetiva:

Se pensarmos na crise atual, Lacan permanecerá essencial, pois tenta retomar, dentro da desordem, uma ordem imanente, um enquadramento referencial que se remete ao horizonte do simbólico. Se extrapolarmos a partir do pensamento lacaniano, poderemos dizer que a crise do mundo contemporâneo é uma crise (do) simbólica (o).[...] O que Lacan traz hoje em dia é, por conseguinte, duplamente fundamental: 
de um lado, permite que se adquira uma compreensão estrutural nítida da crise enquanto crise (do) simbólica (o); por outro, serve para afirmar a irredutibilidade do sujeito desejante enquanto tal (BADIOU; ROUDINESCO, 2012, p. 86-87).

Se transpusermos as palavras de Lacan, inserindo-as no contexto épico, poderemos encontrar uma resposta à massificação imposta aos seres humanos pelos seres divinos, buscando na subjetividade, no embate com o Real, a evasão de um mundo de reificação, o confronto com uma verdade que pode gerar a vida verdadeira. Para Aquiles, a morte não mais figurativiza o Mal, mas torna-se parte da ideologia ética que renova a ideia de vida autêntica.

Seria Aquiles um protagonista da ética das verdades? Ou a personagem do mundo grego encarna a obediência ao destino, desresponsabilizando-se de seu papel de sujeito e anulando qualquer possibilidade de participação ativa no contexto no qual se insere? Certamente, há duas facetas do mesmo herói, sintoma que o torna ainda mais complexo e próximo do sujeito do cosmos contemporâneo. O que é, finalmente, ponto pacífico para Žižek e para Badiou é a necessidade de ruptura para que as coisas não permaneçam como estão, para que a ordem simbólica seja quebrada e uma mudança efetiva do pensamento aconteça.

\section{Referências}

ARENDT, Hannah. A condição humana. 3 ed. Trad. Roberto Raposo. Rio de Janeiro: Forense-Universitária, 1987.

BADIOU, Alain. Ética: um ensaio sobre a consciência do mal. Trad. Antônio Trânsito e Ari Roitman. Rio de Janeiro: Relume - Dumará, 1995.

. Ethics: An Essay on the Understanding of Evil. New York: Verso, 2002.

. Para uma nova teoria do sujeito. Trad. Emerson Xavier da Silva. Rio de Janeiro: Relume Dumará, 1994.

BADIOU, Alain; ROUDINESCO, Élisabeth. Jacques Lacan, passado presente. Trad. Jorge Bastos. Rio de Janeiro: Difel, 2012.

BAUMAN, Zygmunt. Identidade: entrevista a Benedetto Vecchi. Trad. Carlos Alberto Medeiros. Rio de Janeiro: Jorge Zahar Ed., 2005.

BENJAMIN, Walter. Obras escolhidas: Magia e técnica, arte e política. Trad. Sérgio Paulo Rounet. São Paulo: Brasiliense, 1994.

BERMAN, Marshall. Tudo que é sólido desmancha no ar. Trad. Carlos Felipe Moisés, Ana Maria L. Ioriatti. São Paulo: Editora Schwarcz, 1998.

COMMELIN, Pierre Marie. Mitologia grega e romana. Trad. Thomaz Lopes. Rio de Janeiro: Tecnoprint, s/d. 
FEHÉR, Ference. O romance está morrendo (Contribuição à Teoria do Romance). Trad. Eduardo Lima. Rio de Janeiro: Paz e Terra S/A. 1972.

HOMERO. A Ilíada. Tradução e adaptação de Fernando C. de Araújo Gomes. Rio de Janeiro: Tecnoprint, s/d.

LUKÁCS, Georg. A teoria do romance. Trad. José Marcos Mariani de Macedo. São Paulo: Duas Cidades, 2000.

MOURA, Rosa. A cidade vigiada. The Truman Show, de Peter Weir, 1998. In: CICLO CINEMACIDADE - PUCPR, maio 2004. Disponível em: http://www.vitruvius.com.br/arquitextos/arq053/arq053 02.asp. Acesso em: 20/01/2016.

ZILLES, Urbano. A imortalidade da alma em Platão e Plotino. Veritas: Revista Trimestral de Filosofia da PUCRS. Porto Alegre, v. 48, n. 4, p. 603 -612, dez. 2003.

ŽIŽEK, Slavoj. How to read Lacan. New York, London: W.W. Norton Company, 2006.

\section{Immortal subject, interpassive subject: the ambiguity of the epic character}

Abstract: Transcending the human potentialities, the human animal reaches the status of immortal when resists and overcomes himself. Thus occurred with the Christian martyrs and also with the archetypes from universal epic. For Badiou (2002), the immortality, in short, consists in the man's attitude who becomes subject before an event, in other words, that, from a moment of epiphany, it submits to the truth from the exceptional event, being called up to a fidelity. On the other hand, in addition to the immortality process, the interpassivity's concept, exposed from Slavoj Žižek's studies (2006) and from its reading of Lacanian work, reveals another side to the epic characters, once that this heroes act through the Olympic Gods' work; even seeming an active personality, the characters don't act by free will and yes, to fulfill the pre-established by deities. It is intended, in this Article, to reflect about the dialogism immortal subject $\mathrm{X}$ interpassive subject, pointing marks of both domains in the world epic.

Keywords: Immortality. Interpassivity. Epic Character.

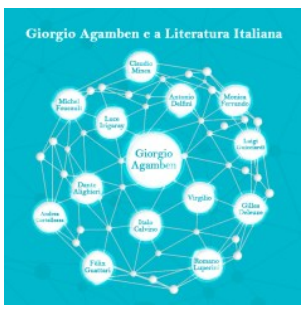

